\title{
Health manpower development in Nepal: A historical perspective
}

\author{
Shah M \\ Consultant Surgeon, Former Dean of Institute of Medicine, Maharajgunj, Nepal.
}

$\mathrm{T}^{\circ}$ o the architect, perspective is representation on paper of 3- dimensional objects but, figuratively, perspective is the relation in which parts of a subject are viewed by the mind ${ }^{1}$. It has taken several decades for the perspectives of the history of health manpower development in Nepal to be indicated by the events and publications that have taken place.

I wish to begin by emphasizing that anyone with interest in health manpower development should also take interest in health care planning and services. My interest in these fields developed during my undergraduate clinical years in $1955 \mathrm{CE}$ when I utilised the opportunities to visit my senior friends, who were newly posted as medical officers in the districts of Osmanabad, Nizamabad etc, during the summer vacations. Our training was based on the undergraduate curricula of Cambridge ${ }^{2}$ and Harvard but my friends had to practise under deplorable conditions. We, the "horses", were being trained up to the "best international standards" but the Indian Medical Council had not found out the condition of the "carriages" to be served by us, and the carriages were dilapidated and unfit for the journey.

During the British colonial days in India, the purpose of any health services was mainly to prevent epidemics in their military cantonments ${ }^{3}$. The Civil Surgeon doctors' in charge were mostly Whites. In 1943 i.e. four years before independence, the Viceroy had appointed a Committee to review the existing health situation and to recommend the future health care organisation, under the chairmanship of Sir Joseph Bhore. This Bhore Committee had submitted its report in 1946 in 4 volumes, recommending comprehensive curative and preventive health services be started immediately in all parts of India, for medical relief, control of communicable diseases, environmental sanitation, maternal child health care, collection of vital statistics, Health Education and School Health Service. The Primary Health Centres were to be the focal points for these services, one for every 40,000 of the population and having 30 beds and 3 sub-centres and a total staff of 2 medical officers, 1 nurse, 4 public health nurses, 2 health assistants, 2 sanitary inspectors, 4 midwives, 4 trained dais and 15 class IV staff, and compulsory 3- months field training in preventive and social medicine for every medical officer ${ }^{4}$.

This important report became the basis of health planning in India's first four Five- year Plans from 1951 to 1974. As the Health Assistants were not available for quite a while, temporarily 2 compounders were substituted for them.

About the implementation of the Health Plans based on this Report, Carl Taylor, N. Jungalwala and many others have written books e.g. "The Health Centre doctor in India" "The Narangwal Project Results" $"$ and "Doctors for the villages"?

After working on the Osmania General Hospital in the 1957 Influenza Pandemic, and at the Cholera Hospital of Kathmandu in the 1958 Cholera Epidemic, I became a Permanent Cadre Medical Officer of HMG at the salary of Rupees 180 and allowance of Rupees 20 per month, and had a spell as the Superintendent in 1958 of the Civil Medical School. In 1972, I was the chairman of Tribhuvan University's Ayurved Curriculum Committee in which the Director of Health Services Dr. Gauri Shankar Lal Das was also a member. So I am aware that the training of Compounders and Dressers was started in Nepal in 1934, and the training of Ayurved physicians began in 1933 .

In 1962, HMG Ministry of Health requested WHO SEARO for the assignment of a Short- term Consultant to report on the proposed establishment of a Medical College in Nepal. WHO made a good choice in Professor W. Melville Arnott (professor of medicine at UK's Birmingham University) who had been Rapporteur of WHO Geneva's 4 to 8 December 1961 Study Group on "Internationally Acceptable Minimum Standards of Medical Education"s. One sentence from this Group's Report is sufficient justification of this choice. "The basic purposes of a medical school are

Correspondence

Dr. Moin Shah

Consultant Surgeon, Former Dean of Institute of Medicine, Maharajgunj, Nepal 
to promote good physicians, to promote by example a high standard of medical care, and to prosecute and encourage research."

Professor Arnott's assignment report ${ }^{9}$ was of a high quality. For example, the description in it of the objectives of medical undergraduate education was so good that the UK's General Medical Council moved, 4 years later, to change the 1858 Medical $\mathrm{Act}^{10}$.

Yet the assignment report severely displeased some doctors of Nepal, therefore I shall quote the notes I had made from the report, at full length because the report deserved to be understood and appreciated:-

Quotation 1: "Health assistants man some 60 centres all over the country, with their energy devoted to curative medicine and there is no effective system of supervision of these Centres by fully trained medical men...... The problem in Nepal is to arrive at a reasonable public health and medical service for the whole country including its rural areas in the shortest possible time....... The solution lies in the deployment of health auxiliaries and sanitary assistants in health centres under the Supervision of fully qualified doctors."

Quotation 2: "One finds that the needs of various countries will impose varying demands. In some countries the principal need is for physicians to take charge of rural areas in which they must be, in a large measure, self sufficient. In other more urbanized countries a greater degree of specialization e.g. in Surgery, Internal Medicine, and the various subdivisions of these, is important. It is hoped that a Medical College in Nepal would produce graduates who regarded preventive medicine as at least as important as curative medicine and who would unhesitatingly regard the provision of a deep well and efficient latrine in every Village, for instance, as of far greater importance than the acquiring of facilities for Cardiac Surgery. Such an attitude does not by any means come naturally, as medical education has in the past concerned itself with the curative and ameliorative aspects of individual instances of illness and injury, almost to the exclusion of preventive measures."

Quotation 3: "To leave the doctors to earn most of their livelihood in private practice is invariably unsatisfactory in an under-developed under-doctored country....... It is universal experience that where the doctors of a country derive most of their income from private practice, they congregate in the main population centres, to the grave detriment of the rural areas. This is seen even in such a highly developed country as the USA where there are extensive rural areas; in Kentucky, for example, there are very few doctors. This has been largely overcome in the UK where the vast majority of doctors derive the bulk of their income from the National Health Service. This is a satisfactory but immensely costly solution. Another method (which would seem to be the only one open to a country like Nepal) is to require newly qualified to serve for a period of several years in a whole time capacity (preferably without the right to private practice) wherever they may be sent. Thereafter some influence on their distribution can continue to be exerted by the existence of remunerated "part- time" posts in government service. An inescapable corollary to this surrender of freedom by the doctors is the provision of financial support for those who require it during their period of compulsory service."

Next, when Dr. Mahendra Prasad was the Director of Health Services, the Government of Nepal in 1965 requested the Government of India for the services of Dr. P.M. Bhandarkar MS, FCPS, the Maharastra Government Surgeon- General, to report "on the feasibly of starting a Medical College In Nepal.” Dr. Bhandarkar visited Kathmandu, Patan, Pokhara and Biratnagar over 2 weeks in October 1965. It appears that Dr. Bhandarkar had not read Prof. Arnott's assignment report, but his assignment report ${ }^{11}$ did not in any way contradict Prof. Arnott's report. Dr. Bhandarkar wrote: "The Medical College should be under Tribhuvan University...... The training should be for a minimum period of 4 years on the pattern of Medical Colleges in India which is accepted by the Medical Council of India and there should be internship of one year...... All the teaching staff should be non- practising....... The Government will have to see that all medical officers trained nationally are made to serve the Government by providing a bond which should be enforced rigidly...... It is very essential that all persons qualifying as doctors will serve under the government for at least 5 years, longer if required, at least 2 years being in the hills......."

On 6August 1965, Queen Elizabeth the second appointed a Royal Commission on Medical Education under the chairmanship of Baron TODD "to review medical education, undergraduate and postgraduate......" In April 1968, this TODD commission submitted a 400 page report to the Queen ${ }^{12}$. This important report is still held in a high esteem. For example, two months ago, Professor Sam Lienster the Dean of the University of East Anglia, had high praise for this report. Of its many recommendations, one was that when health manpower is being developed in the country, national needs are of supreme importance.

Then in June 1968, I left my surgical practice in the UK and returned to Nepal as a Senior Surgeon of Bir Hospital, a post I held until 1982. 
The final perspective, even a milestone, in the Phase I of the historical perspectives described today is the beautiful book "A Report on Health and Health Administration of Nepal"13 which did not include the author's name in it. Still this report should have received the wide appreciation it deserved because it was of a high standard and very useful too. It had even a one and half pages long article on the Nepal Medical Association!

Phase II of the historical perspectives of health manpower development in Nepal, covering the 10 years 1969 to 1979 , will be described on another occasion.

This paper was presented on $17^{\text {th }}$ April 2009 at the $24^{\text {th }}$ All Nepal Medical Association Conference (ANEMECON)

\section{References}

1. Oxford University. The Concise Oxford Dictionary. 3rd edition. Oxford: Oxford University Press; 1934.

2. Cambridge University. Student's Handbook to the University and Colleges of Cambridge. United Kingdom: Cambridge University Press; Jun 1950.

3. Ramasubban R. Public Health and Medical Research in India: Their Origin under the impact of British Colonial Policy. Stockholm: SAREC; 1982.

4. Bhore J. Report of the Health Survey and Development Committee. 4 Volumes. Simla: Government of India Press; 1946.

5. Takulia HS, Taylor CE, Sangal SP, Alter JD. The Health Centre Doctor in India. Baltimore: The Johns Hopkins Press; 1967.
6. Taylor CE, Sarma RSS, Parker RL, Reinke WA, Faruquee R. Child and Maternal Health Services in Rural India, the Narangwal experiment: Integrated Family Planning and Health Care. Baltimore, US: Johns Hopkins University Press; 1983. p. 252.

7. Taylor CE, Alter JD, Grover PL, Sangal SP, Andrews S, Takulia HS. Doctors for the Villages. London: Asia Publishing House; 1976.

8. World Health Organisation. Internationally Acceptable Minimum Standards of Medical Education. Geneva: World Health Organisation; 1962.

9. Arnott WM. Assignment Report on the Proposed Establishment of a Medical College in Nepal. New Delhi: WHO Regional Office for SouthEast Asia; 2 Apr 1963.

10. General Medical Council. Recommendations as to Basic Medical Education. UK: General Medical Council; 1967.

11. Bhandarkar PM. Assignment Report on the Feasibility of Starting a Medical College in Nepal. Kathmandu: Indian Aid Mission; Nov 1965.

12. Townsend E. Royal Commission on Medical Education 1965-68 report. J R Coll Gen Pract. 1968; 16(3): 245-7.

13. His Majesty's Government Ministry of Health. A Report on Health and Health Administration of Nepal. Kathmandu: His Majesty's Government Ministry of Health; 1969. 